\title{
Research into the psychological well-being of young refugees
}

\section{Winnie Lau ${ }^{1,2}$ and Trang Thomas ${ }^{1}$}

\author{
${ }^{1}$ School of Health Sciences, Royal Melbourne Institute of Technology - City Campus, Melbourne, Victoria, Australia \\ ${ }^{2}$ Australian Centre for Posttraumatic Mental Health, PO Box 5444, Heidelberg West, VIC 3081, Australia, email wlau@unimelb.edu.au
}

\begin{abstract}
nterest in the psychological well-being of refugees and asylum seekers has steadily grown in recent years. Latest estimates indicate there are 32.9 million people of concern to the United Nations High Commissioner for Refugees (2006). A refugee is defined as being in that position because of a well-founded fear of persecution due to race, religion, nationality, social group or political opinion, and who is consequently outside and unable to return to his or her country. The status of 'refugee' is contrasted with that of a person seeking asylum, whose experiences may be similar but who is not formally determined in the same way.

The literature reporting mental health research concerning young refugees and asylum seekers is less comprehensive than that concerning adults. This is remarkable, given that almost half the world's refugees are children and adolescents (United Nations High Commissioner for Refugees, 2006). This paper summarises key research findings about the psychological well-being of child and adolescent refugees and asylum seekers. A full review has been presented by the Australian Human Rights and Equal Opportunity Commission (2002). For brevity, the term 'refugee' will be used hereafter to encompass those also seeking asylum.
\end{abstract}

\section{Symptoms of post-traumatic stress}

Many young refugees migrate with histories of exposure to trauma. Such trauma may include the violent death of a parent, injury to or torture of a family member, separation from parents, witness of murder or even massacre, exposure to bombardments, shelling or terrorist attack, forcible eviction from home, detention, physical injury and disability inflicted by violence, sexual assault, disappearance of loved ones, enduring political oppression, deprivation of human rights and education, and subjection to childsoldier activities. Children and adolescents are especially vulnerable to these effects because of their incomplete biopsychosocial and cognitive development, dependence, and underdeveloped coping skills. This vulnerability is increased owing to potential under-reporting of symptoms by parents (Almqvist \& Broberg, 1999).

In the main, investigations have considered the impact of traumatic events upon psychological well-being, predominantly in terms of post-traumatic stress disorder (PTSD) or related symptoms. Included within this broader set of symptoms may be presentations of physical discomfort, trauma-themed repetitive play, personality changes, regressive or violent behaviour, high anxiety, social withdrawal, conduct problems or survivor guilt.

Despite controversy surrounding the application of the term PTSD to populations affected by war (arguably, this diagnostic approach 'pathologises' normal reactions to abnormal situations), many studies have shown that trauma symptoms are common among young refugees. The studies by Kinzie et al (1986) and Sack et al (1999) are frequently cited to attest to the persistence of post-traumatic stress and poor adaptation in young refugees exposed to trauma as children. Others have successfully used interviews with children to identify a large, otherwise hidden, proportion who were not known by their parents to have symptoms, yet who had a diagnosis of PTSD (Almqvist \& Brandell Forsberg, 1997).

While the nature of traumatic exposure varies, from direct to indirect and from single to repeated events, post-traumatic stress is well established in young refugees from many different regions, including, for example, Bosnia (Papageorgiou et al, 2000), Central America (Rousseau et al, 1997), Iran (Almqvist \& Broberg, 1999) and Somalia (Ellis et al, 2008). Although prevalence rates of PTSD are highly variable (from $2 \%$ up to $50 \%$; Howard \& Hodes, 2000), there is general support for the validity of the diagnosis as a useful construct in children, cross-culturally.

Studies have also examined the impact of trauma before immigration, in relation to its type, amount and duration. Review of such studies indicates that the greater the severity, number and extent of exposures, the poorer the psychological outcome in terms of onset and severity of PTSD symptoms (Papageorgiou et al, 2000). For example, children directly exposed to violence (e.g. an assault on parents) or multiple trauma (e.g. shelling, combat) have a greater risk of developing chronic or severe PTSD (Almqvist \& Brandell Forsberg, 1997).

Although it is not yet established whether the legacy of exposure to traumatic stress is carried into adulthood, longitudinal studies do show that while the severity of these symptoms may lessen, they nevertheless persist over time in up to a third of young refugees, causing continued distress (Sack et al, 1999). Another consistent finding is that disorders cluster in families, with the risk of PTSD increasing when a parent or other family member exhibits PTSD (Sack et al, 1996). Young refugees are also susceptible to vicarious trauma; in such cases a parent's own traumatic experience can influence the symptoms experienced by the children (Hodes, 2000). 
Although consistent outcomes are reported in the literature for young refugees regardless of the type of traumatic experiences and cultures, the specific impact of trauma within a cultural context has rarely been examined. There is, though, increasing evidence that trauma symptoms are influenced by culture (Rousseau et al, 1997).

\section{Comorbidity and other psychological outcomes}

Adverse psychological outcomes are exacerbated by problems of malnutrition, disease, physical injuries, brain damage and sexual abuse. These should not be overlooked when making psychological enquiries of young refugees.

Disorders that are commonly associated with PTSD include high rates of anxiety and depression, with the latter being more closely associated with ongoing adversity during resettlement (Sack et al, 1996). Somatic complaints include sweating, headaches, respiratory and gastric problems. Cognitive problems include negative beliefs, expectations and suicidal thoughts. In displaced children, eating and sleep disorders are reported to accompany uncertainty regarding current status and fears about the future (Kocijan-Hercigonja et al, 1998). Among adolescents, a small number experience psychoses (Hodes \& Tolmac, 2005). In terms of psychosocial outcomes, young refugees experience learning difficulties, isolation and social disadvantage (Howard \& Hodes, 2000).

It should be noted that there is inconsistency in reports, with some studies documenting equivocal findings concerning the prevalence of mental health disorder among refugee children. Rather than suggesting an absence of distress, this may indicate that symptoms can be transient. Alternatively, psychopathological outcomes may form only part of the short- and long-term trauma response, which includes not only PTSD, anxiety and depression, but also other negative outcomes, such as loss and grief (Howard \& Hodes, 2000).

Moreover, there is good evidence that, despite multiple traumas and elevated prevalence rates in young refugees, adaptation does occur (Punamaki et al, 2001). That there is resilience and recovery, after multiple loss and hardship, is reassuring. None the less, when compared with non-refugees, there is significantly greater psychological disturbance in young refugees. For example, psychological disturbance is three times greater among refugee children in Britain than among children in the general population (Fazel \& Stein, 2003).

\section{Risk and protective factors}

This discussion has highlighted the fact that specific premigration risk factors, including trauma exposure and forced migration, are the most detrimental. Previous research also identifies dispositional and environmental factors as predictors of mental health. An ability to respond to new situations, positive self-esteem, good temperament and positive support through strong peer relationships are protective factors (Almqvist \& Broberg, 1999).

The risk and protective factors during the post-migration period are equally important. This is because ongoing resettlement stressors can significantly undermine wellbeing. As is the case before migration, existing mental health problems, family dysfunction, parental incapacity and unavailability (especially maternal in origin) are critical post-migration risk factors (Almqvist \& Broberg, 1999). Furthermore, stressors that occur during resettlement can exacerbate or reactivate memories and emotions of past trauma.

It has been consistently shown that young refugees who are unaccompanied or who have been separated from their families have a greater risk of mental health problems than those who are accompanied or who later re-establish contact with their family (Sourander, 1998). Because of their heightened vulnerability to being forced to undertake child-soldier activity as well as their greater potential to support a family financially at resettlement, boys are highly represented in this unaccompanied group (Rousseau et al, 1997). The risk to unaccompanied minors is exacerbated following a history of multiple separations (Rousseau et al, 1997) and when caregivers other than the natural parents are substituted at resettlement (Kinzie \& Sack, 1991).

Displacement and the processes associated with seeking asylum pose risks to young refugees for many reasons. These include the compounding stressors of camp life, enforced supervision and communal living outside the family and/or cultural group. The risk of mental health problems is also increased by delays in processing immigration status, dealing with officials, racism and discrimination, uncertainty about asylum status, loneliness and boredom (Silove et al, 1997). In Australia, mandatory detention has now been abandoned as a government policy: while in operation it increased the risks of hopelessness, despair and self-harm among those seeking asylum (Fazel \& Silove, 2006). Negative outcomes associated with displacement and detention may also be attributable to the loss of traditional parent roles, perceived control and learned helplessness.

Acculturative stressors, including low socio-economic status, problems in language and school adjustment also predict poor adaptation. By contrast, good academic achievement, as influenced by language acquisition and good peer relations, is predictive of adaptation (Rousseau et al, 1997). Importantly, discrimination and financial hardship have been shown to predict depression in the resettlement period (Ellis et al, 2008), supporting the strong association between depression and acculturative stress (Sack et al, 1996). Conflict in adolescent identity formation is related to poor psychological adjustment. The process of adapting to a new culture can further increase vulnerability through high parental expectations and intergenerational conflict (Rousseau et al, 1997).

There are contradictory findings regarding the influence of age and gender on risk of mental health problems among immigrant children. While some suggest cognitive immaturity in younger children is protective (Papageorgiou et al, 2000), others have suggested that an inability to articulate and express distress on the part of younger children may increase risk (Berman, 2001). Girls and boys are more vulnerable at different ages and in rather different conditions (Papageorgiou et al, 2000). Of course, differences in gender may reflect cultural expectations for the display of emotions.

The availability of social support and positive peer relationships can facilitate successful adaptation in the resettlement period despite a history of extreme trauma (Almqvist \& Broberg, 1999). The maintenance of close ethnic community ties is also protective, alongside cultural and religious traditions, which assist in restoring a sense of continuity 
(Rousseau et al, 1997). Despite low rates of help-seeking, early intervention and appropriate psychosocial assistance have been reported as crucial protective factors (Howard \& Hodes, 2000; Punamaki et al, 2001).

\section{Conclusions}

Unfortunately, the major risk factor is traumatic war exposure, and that cannot be eliminated. Let us remember, though, that with knowledge of the factors that are significant, especially those that enhance resilience, we can help to minimise the burdensome effects of trauma and give strength to this vulnerable and growing population.

\section{References}

Ajdukovic, M. \& Ajdukovic, D. (1998) Impact of displacement on the psychological well-being of refugee children. International Review of Psychiatry, 10, 186-195.

Almqvist, K. \& Brandell Forsberg, M. (1997) Refugee children in Sweden: post-traumatic stress disorder in Iranian preschool children exposed to organized violence. Child Abuse and Neglect, 21, 351-366.

Almqvist, K. \& Broberg, A. G. (1999) Mental health and social adjustment in young refugee children $3 \frac{1}{2}$ years after their arrival in Sweden. Journal of the American Academy of Child and Adolescent Psychiatry, $38,723-730$

Berman, H. (2001) Children and war: current understandings and future directions. Public Health Nursing, 18, 243-252.

Ellis, B. H., Macdonald, H. Z., Lincoln, A. K., et al (2008) Mental health of Somali adolescent refugees: the role of trauma, stress, and perceived discrimination. Journal of Consulting and Clinical Psychology, 76. 184-193.

Fazel, M. \& Silove, D. (2006) Detention of refugees. BMJ, 332, 251-252.

Fazel, M. \& Stein, A. (2003) Mental health of refugee children: comparative study. BMJ, 327, 134

Hodes, M. (2000) Psychologically distressed refugee children in the United Kingdom. Child Psychology and Psychiatry Review, 5, 57-68.

Hodes, M. \& Tolmac, J. (2005) Severely impaired young refugees. Clinical Child Psychology and Psychiatry, 10, 251-261.
Howard, M. \& Hodes, M. (2000) Psychopathology, adversity, and service utilization of young refugees. Journal of the American Academy of Child and Adolescent Psychiatry, 39, 368-377.

Human Rights and Equal Opportunity Commission (2002) Psychological Well-Being of Child and Adolescent Refugees and Asylum Seekers: Overview of Key Research Findings of the Past 10 Years. National Inquiry Into Children in Immigration Detention, Human Rights and Equal Opportunity Commission (HREOC). Available at http://www. humanrights.gov.au/about/media/media_releases/2002/31_02.html (accessed May 2008).

Kinzie, J. D. \& Sack, W. (1991) Severely traumatized Cambodian children: research findings and clinical implications. In Refugee Children: Theory, Research and Services (eds F. L. Ahearn \& J. L. Athey), pp. 92-105. Johns Hopkins University Press.

Kinzie, J. D., Sack, W. H., Angell, R. H., et al (1986) The psychiatric effects of massive trauma on Cambodian children: I. The children. Journal of the American Academy of Child Psychiatry, 25, 370-376.

Kocijan-Hercigonja, D., Rijavec, M. \& Hercigonja, V. (1998) Mental health condition and adjustment of refugee and displaced children in a war area. Psychiatria Danubina, 10, 13-29.

Papageorgiou, V., Frangou-Garunovic, A., lordanidou, R., et al (2000) War trauma and psychopathology in Bosnian refugee children. European Child and Adolescent Psychiatry, 9, 84-90.

Punamaki, R. L., Qouta, S. \& El-Sarraj, E. (2001) Resiliency factors predicting psychological adjustment after political violence among Palestinian children. International Journal of Behavioral Development, 25, 256-267.

Rousseau, C., Drapeau, A. \& Corin, E. (1997) The influence of culture and context on the pre- and post-migration experience of school aged refugees from Central America and Southeast Asia in Canada. Social Science and Medicine, 44, 1115-1127.

Sack, W. H., Clarke, G. N. \& Seeley, J. (1996) Multiple forms of stress in Cambodian adolescent refugees. Child Development, 67, 107-116.

Sack, W. H., Him, C. \& Dickason, D. (1999) Twelve-year follow-up study of Khmer youths who suffered massive war trauma as children. Journal of the American Academy of Child and Adolescent Psychiatry, 38, 1173-1179.

Silove, D., Sinnerbrink, I., Field, A., et al (1997) Anxiety, depression and PTSD in asylum-seekers: associations with pre-migration trauma and post-migration stressors. British Journal of Psychiatry, 170, 351-357.

Sourander, A. (1998) Behavior problems and traumatic events of unaccompanied refugee minors. Child Abuse and Neglect, 22, 719-727.

United Nations High Commissioner for Refugees (2006) UNHCR Statistical Online Population Database. Available at http://www.unhcr. org/statistics/populationdatabase (accessed May 2008).

\section{Estonia}

\section{Anne Kleinberg}

Secretary General, Estonian Psychiatric Association, email anne.kleinberg@lastehaigla.ee

\begin{abstract}
- stonia is a small country $\left(45000 \mathrm{~km}^{2}\right)$ with a population - of 1.3 million people. It has undergone rapid change since it gained independence from the Soviet Union in 1991. It has achieved some economic success, although there is a suggestion that this has been at the expense of the mental health and general emotional well-being of the people. In the Estonian Health Interview Survey, depressive symptoms were observed in $11.1 \%$ of respondents and their presence was strongly correlated with socio-economic status (Aluoja et al, 2004).
\end{abstract}

\section{Health system}

The Estonian health system is funded via a national social insurance scheme. The Health Insurance Fund is provided from taxes on incomes of the working population, but it also covers those who have no income from employment. It is a universal scheme, under which medical institutions are reimbursed for treatments provided to all patients.

The first point of contact for the patient is the family doctor. Where necessary, the family doctor can refer the 